\title{
Municipal community gardens in the metropolitan area of Milano. Assessment and planning criteria
}

\author{
Giulio Senes, Natalia Fumagalli, Paolo Stefano Ferrario, Daniele Gariboldi, Roberto Rovelli \\ Department of Agricultural and Environmental Sciences, University of Milano, Italy
}

\begin{abstract}
A community garden (CG) can generally be defined as a piece of land gardened collectively by a group of people that grow their produce on shared lots that have been divided into smaller plots. Some gardens are grown collectively, are divided into different plots for individual and family use; CGs are usually located in urban or peri-urban areas. As a growing portion of the urban open space network, CGs are contributing to land preservation, access to open space, and sustainable re-use of vacant land. They promote healthy communities and provide food security for many. In this context, the object of the study are the municipal community gardens (MCGs), a specific typology of CGs provided for land-use planning legislation and practice as an urban service with social function, made available to the community by the municipalities and assigned to be cultivated to citizens (usually seniors/retired people). In particular, the study aimed: i) to evaluate the presence of MCGs in the città metropolitana di Milano (the former province of Milano); and ii) to define criteria for new MCGs settlement, using existing geo-database and geographical information system to make it replicable in other settings. For the first topic the 133 municipalities of the former province of Milano (excluded the city of Milano) were analysed. Only 59 municipalities had presence of MCGs. The average area per capita of MCGs is $0.68 \mathrm{sq} . \mathrm{m} / \mathrm{inh}$ ab. (if we exclude Rodano, an outlier with 35 sq.m/inhab.). An overlay with land use map has permitted to define the relationships between the MCGs and their surrounding territory. The major part of MCGs are included in urban or suburban areas. For the second goal, the land area to be allocated for new MCGs was assessed for each municipality, comparing area of existing MCGs and a minimum required area (calculated on the basis
\end{abstract}

Correspondence: Giulio Senes, Department of Agricultural and Environmental Sciences, University of Milano, via G. Celoria 2, 20133 Milano, Italy.

E-mail: giulio.senes@unimi.it

Key words: Landscape planning; community gardens survey; urban agriculture.

Received for publication: 7 September 2015.

Accepted for publication: 11 February 2016.

(C) Copyright G. Senes et al., 2016

Licensee PAGEPress, Italy

Journal of Agricultural Engineering 2016; XLVII:509

doi:10.4081/jae.2016.509

This article is distributed under the terms of the Creative Commons Attribution Noncommercial License (by-nc 4.0) which permits any noncommercial use, distribution, and reproduction in any medium, provided the original author(s) and source are credited. of the inhabitants number). Finally a method was proposed to locate the new MCGs areas. Criteria used to identify suitable areas for new MCGs were: proximity to the road network inside residential areas, suitable land use, not high land capability. In this way it has been defined for each municipality the number of MCGs to be realized and their area, and located the potentially suitable sites. Choosing between the identified suitable areas, the new MCGs were homogeneously located on the territory of each municipality in order to ensure adequate coverage of residential areas; the degree of coverage has been verified through a service area analysis. The proposed method seems to be useful for the MCGs settlement at metropolitan/provincial level.

\section{Introduction}

In urban areas a wide range of ecosystems and land uses provide different services including microclimate regulation, air filtration (gas regulation), noise reduction (disturbance regulation), rainwater drainage (water regulation), sewage treatment (waste treatment), and recreational, cultural and educational values (Costanza et al., 1997; Alberti, 2005). Other services such as food production and erosion control usually have a limited significance within urban boundaries, but may become relevant when looking at metropolitan area contexts (La Rosa et al., 2016).

Urban planners are increasingly interested in maintaining agriculture within and around cities due to food security concerns. Urban agricultural (UA) systems appear in many forms - from community farms and rooftop gardens to edible landscaping and urban orchards and can be productive features of cities and provide important environmental services (Lin et al., 2015).

Community gardens fall under the umbrella of UA, defined as the growing of plants and the raising of animals within and around cities (FA0, 2014). Community gardens are often small-scale, and highly patchy cultivated areas, and are usually located in urban or peri-urban areas for food production (Colding et al., 2006). A community garden (CG) can generally be defined as a piece of land gardened collectively by a group of people that grow their produce on shared lots that have been divided into smaller plots (Central Oregon Intergovernmental Council, 2014).

Some gardens (communal gardens or, in Italian, orti condivisi) are, typically organized and gardened collectively by a group of people who share in the work and rewards; plots are not subdivided for individual or family use. Others (neighbourhood community gardens or, in Italian, orti urbani) are divided into different plots for individual and family use (University of Missouri, 2009).

Many CGs have both common areas with shared upkeep and individual/family plots. The land may produce fruit, vegetables, and/or ornamentals (Rosol, 2010; Bendt et al., 2012).

CGs are typically managed by the local administrations with different names in the world: kleingarten in Austria, Swiss and Germany, ogròdek dzialkòw in Poland, kirsketk in Hungary, volkstuin in Holland 
and Belgium, jardins ouvriers or jardins familiaux in France, kolonihave in Denmark, koloniahage in Norway, koloniatratgard in Sweden, siirtolapuutarhat in Finland, shimin-noen in Japan and orti sociali in Italy (Groening, 2005).

Unlike public parks and other green spaces maintained by local governments, CGs are generally managed and controlled by a group of unpaid individuals or volunteers - usually the gardeners themselves. There are many variations on the theme of community gardening. For instance, a CG may: i) have a closed or open gate policy, making it enclosed and private or open and public; ii) be one large shared area or individual plots for each gardener; iii) incorporate a mix of food plantings and ornamental plantings; iv) be located in urban, suburban, or rural neighbourhoods; v) be used for educational purposes with local communities and schools; vi) have a greenhouse on site for cultivating seedlings; vii) house seed storage facilities for preserving heritage varieties of plants; viii) incorporate other environmental programs, such as butterfly gardens or methods of providing wildlife habitats.

As a growing portion of the urban open space network, CGs and gardeners are contributing to land preservation, access to open space, and sustainable uses of usually otherwise vacant land. This typology promotes healthy communities and provides food security for many (Orsini, 2013). Aside from the main function of food production, CGs have exhibited a plethora of ecological, social, and economic benefits (Ghosh, 2004). CGs contribute to an increasing diversity of land use by both humans (cultural traditions) and biota (biodiversity) (Irvinea et al., 1999). More specifically this includes aesthetic improvements, regulation of microclimate in urban areas, a reduction in transportation costs, increased soil health, increased public health (van den Berg et al., 2010) and increased interactions between humans (Kaplan, 1995), other life forms, and biological processes. The reduction of storm water runoff due to rainwater harvesting and replacement of hard surface with CGs is part of the green infrastructure strategies (Angotti, 2015).

In aesthetic terms, the CGs areas are more orderly in appearance when the site changing from being abandoned to productive. In social terms, the feeling of safety might apply in CGs, they provide the local residents with a feeling of increased security because the creation of gardens can eliminate illegal uses ant revitalize neighbourhoods. Finally the gardeners become the managers of the suburban green spaces at no cost to the community (Brock and Foeken, 2006).

However, compared to crops from rural sites, horticultural crops in urban or peri-urban areas are generally exposed to a higher level of pollutants including trace metals and organic contaminants depending on local traffic, crop species, planting style and building structures (Qadir et al., 2000; Säumel et al., 2012). Moreover, agricultural water runoff during peak rainfalls could be a problem for surface water quality and public health if urban gardeners use chemical fertilizers and pesticides without control (Angotti, 2015; Muratet and Fontaine, 2015).

In planning terms, distinct from top-down efforts by government organizations to create green spaces such as botanical gardens, community gardens are bottom-up, community-based, collaborative efforts to grow food (Okvat and Zautra, 2011). Garden programs are praised and supported as local action to serve environmental, social, and individual objectives but CGs are largely ignored in planning process, because they are perceived as opportunistic and temporary (Lawson, 2004).

Planners need to consider CGs seriously (Groening, 2005) and municipalities as well as state policy makers, need to develop coherent urban gardening policies: CGs need to become an object of planning (Thibert, 2012). Plots are often located on institutional grounds, vacant land, right of ways (steep slopes, dead ends, under power lines), or marginal areas. CGs need to be better theorized as a planning strategy and integrated into comprehensive plans and frameworks. But before this integration occurs, it would be helpful to know more about commu- nity gardens as a land use and accessibility criteria, so that the benefits of the use can be maximized.

According to sustainable land use planning criteria, the activities must be developed where the necessary natural resources exist and only when the environment is capable of absorbing the impact of these activities (Kozlowski and Hill, 1993; Senes and Toccolini, 1998). To define land uses compatible with new CGs, it is possible apply these methods of sustainable land use planning, using the selection criteria specified by CGs municipal regulations. (Comune di Milano-zona3, 2006; Comune di Sassari, 2013; Comune di Pisa, 2014).

In order to enjoy the opportunities and potential benefits of CGs, users must have reasonable access to these resources. The assessment of accessibility is an aspect often ignored in local services localization. It requires the application of research techniques, supported by geographical information system (GIS) and network analysis instruments, able to relate the characteristics of the users with the territorial and urban components (Somenahalli et al., 2013; Reyes et al., 2014).

In this context, the object of the study is CG as urban service with social function, made available to the community by the municipalities and assigned to be cultivated to citizens (usually seniors/retired people). We call them municipal community gardens (MCGs). We did not take in consideration community gardens included in school, hospitals and nursery homes and community gardens spontaneously promoted by volunteers, associations and citizens on vacant lands. MCGs are planned by municipalities, as part of the zoning process in which each municipality has to define different zones within which various landuses are permitted and provide the minimum ratio value of square meters per inhabitant for public services (among which are included the MCGs). The plots of MCGs are assigned to private citizens for individual or family use.

According with the Regional Law n. 18/2015, Lombardia Region funds the construction of MCGs by municipalities (Regione Lombardia, 2015). To be funded, municipalities have to make a census of public lands available for new MCGs settlements.

Having in mind all of these considerations, we aimed: i) to evaluate the presence of MCGs in the former province of Milano; and ii) to define criteria for new MCGs settlement, using existing geo database and GIS to make it replicable in other settings.

\section{Materials and methods}

The study is divided into two phases (one for each goal) and several sub-phases. For each sub-phase the authors have developed a suitable procedure (Figure 1).

During the first part of the study, the identification and quantification of MCGs in the study area have been performed. The study area is made by the municipalities of the Città metropolitana di Milano (the former province of Milano), with the exception of the town of Milan, for a total of 133 municipalities and an area of about 1400 square $\mathrm{km}(55 \%$ agricultural, $36 \%$ urban, $8 \%$ forest and semi natural, $1 \%$ wetlands and water bodies).

The procedure 1 for the study area definition and MCGs identification and quantification is made by several steps: i) analysis of the municipality land use plans (Piano di Governo del Territorio) of the 133 municipalities, to identify which of them already have or are planning MCGs, and to retrieve any available information about their location, extent and characteristics; ii) analysis of the official web sites of the 133 municipalities, in order to verify the existence of MCGs not included in the plan document; iii) digitization (in ArcGIS; Environmental Systems Research Institute - Esri, Inc., Redlands, CA, USA) of the MCGs areas on the basis of the information contained in the munici- 
pality land use plans and other documents produced by municipalities and by photo-interpretation of digital ortho-photos available on the Lombardia Region Geoportal (owned by AGEA - Agency for payments in agriculture, relief of 2012 with ground resolution of $50 \mathrm{~cm}$ ); iv) ground control through direct survey of the digitized MCGs areas; v) creation of a GIS database of the MCGs areas, using as a basis the same digital ortho-photo; the database was completed with descriptive information associated with each polygon: identification code, name of the municipality, address, area, photographic images, other specific information (Figure 2).

Only 59 of the 133 municipalities analysed have or have planned MCGs.

The procedure 2 starts from the created database and uses GIS technology in order to: i) calculate the average MCGs area per municipality, that will be used in the next phase for the identification of the need for $M C G s$; ii) characterize MCGs with respect to their surroundings, in terms of: landscape (urbanized, agricultural, wood, water) and distance from the urban centres.

In Phase 2, firstly the need for MCGs has been defined for each municipality, calculating: i) the area for new MCGs, based on the difference between the minimum area that each municipality should allocate to MCGs (set equal to the average MCGs area per inhabitant multiplied by the resident population of each municipality), and the area of existing MCGs; ii) the number of MCGs plots, for the municipalities with a lack in MCGs, to be realized, taking as reference value for the

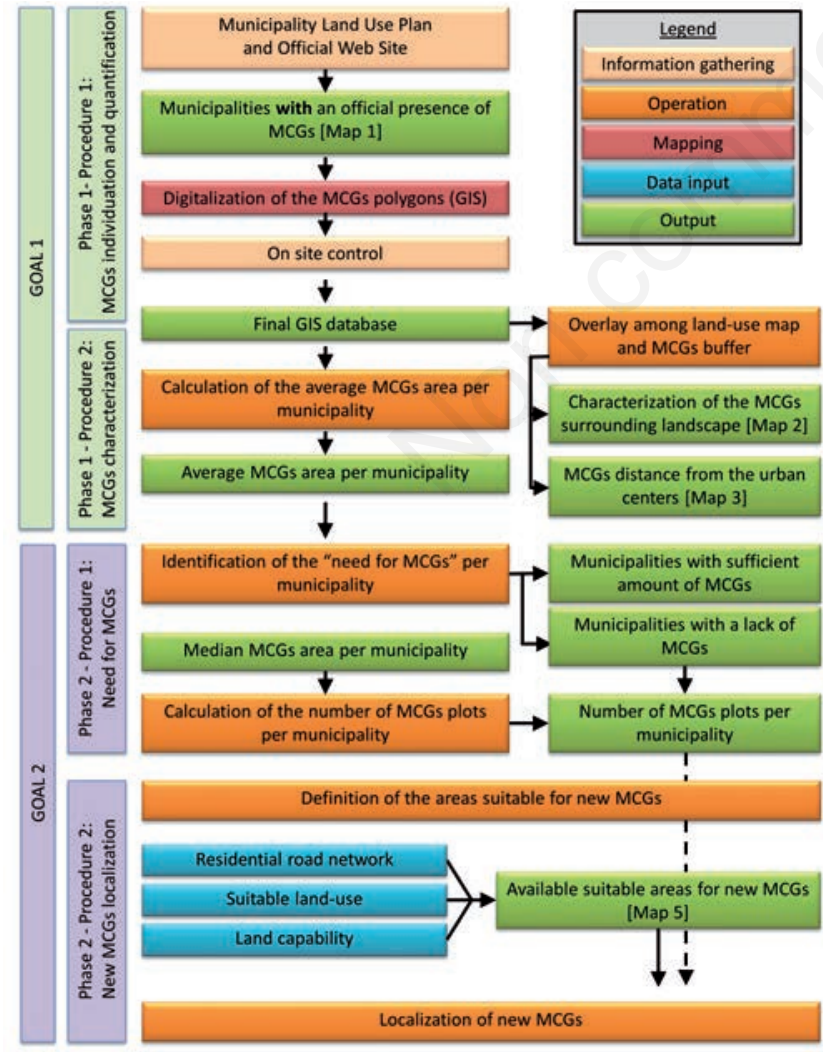

Figure 1. General scheme of the study. MCG, municipal community gardens. single plot the median area of MCGs already existing in the study area.

Then, in order to choose where to localize the new MCGs, it has been: i) firstly, identified the areas suitable for new MCGs, based on proximity to road network in residential areas, land use compatible, not high land capability; ii) secondly, located new MCGs plots, choosing among the suitable areas identified before those capable to ensure a better distribution near the residential areas of the municipalities.

\section{Results and discussion}

During the first phase of the study, the MCGs of the study area have been identified, quantified and characterized. Data have shown that most of the municipalities has a MCG area under 1 square meter per inhabitant, with only 3 municipalities with an area of between 2 and 5 square meters per inhabitant and 1 municipality (Rodano) with a value significantly higher (35 square meters per inhabitant); excluding Rodano, considered an outlier, the average MCGs area per inhabitant in the study area is resulted equal to 0.68 square meters.

The mean is higher than the median (0.48), indicating a positive asymmetric distribution. The third quartile of the municipalities has almost $60 \%$ of the MCGs area. $37 \%$ of the municipalities (21 of 57 ) has a MCGs area per capita greater than average and has the $73 \%$ of the total MCGs area.

Then, in order to characterize MCGs respect to their surroundings, an overlay mapping between the MCGs areas and the land-use map (derived from the Lombardia Region DUSAF database 2012) has been performed, aggregating land-use into four main classes: residential, agriculture, forest, water. Then, two buffer areas around MCGs, with a radius of 330 and 660 meters were identified, corresponding to a walking distance of 5 and $10 \mathrm{~min}$, respectively, at a speed of about $4 \mathrm{~km} / \mathrm{h}$ (Figure 3).

Most MCGs are surrounded by a prevalent urbanized landscape, while the MCGs in agricultural areas are quite distant from the city of Milano. This confirms the role that the MCGs have to allow, in an urban environment, easy access to and contact with nature.

Finally it has been investigated the closer context of the MCGs. All the urbanized land-uses have been extracted from the DUSAF database in order to define the urbanized area and two buffers of 100 meters $\left(1^{\text {st }}\right.$ peri-urban zone) and 200 meters ( $2^{\text {nd }}$ peri-urban zone) from the boundary of the urbanized area have been defined. These buffer dis-

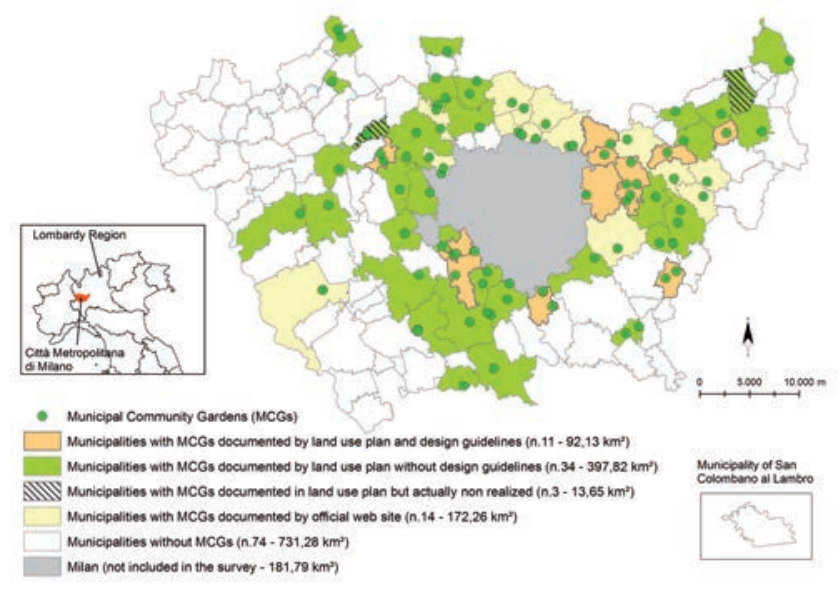

Figure 2. Città metropolitana di Milano: existing municipal community gardens (MCGs) (Map 1). 
tances have been chosen to take into account the level of detail of the DUSAF land-use database $(1: 10,000$, i.e., $1 \mathrm{~cm}=100 \mathrm{~m})$. Overlaying the two buffers with the MCGs it has been possible to verify where they fall (Figure 4): i) $28 \%$ within the urbanized areas; ii) $70 \%$ in the $1^{\text {st }}$ periurban zone; iii) $2 \%$ in the $2^{\text {nd }}$ peri-urban zone.

This data confirm that the municipality usually locate MCGs near urbanized areas in order to ensure a better accessibility, as should be for all social services (Reyes et al., 2014; Wang et al., 2014).

In the second phase, aimed at the planning and localization of new MCGs in each municipality of the study area, firstly the need for MCGs has been defined for each municipality.

In the absence of reference standards derived from the law or literature, it was decided to adopt as a minimum area that each municipality should allocate to MCGs the metropolitan average ( $0.68 \mathrm{sq} . \mathrm{m} / \mathrm{inh}$ abit.). As mentioned, the mean is above the median (0.48), indicating a positive asymmetric distribution (skewness 1.27). However, because the distribution presents a positive kurtosis (equal to 1.1) and then a leptokurtic distribution, that is narrow ( $95 \%$ of the municipalities present a value within the interval of \pm 2 standard deviation), the mean $(0.68)$ has been chosen as reference threshold value.

The difference between the existing MCGs area and the 0.68 represents, for each municipality, the MCGs area to be realized in the future. In 22 municipalities the existing MCGs area is sufficient: typically they are municipalities with a percentage of urbanized area less than $50 \%$ of the municipal area (situated more frequently in the south of Milan).

For the 111 municipalities with an insufficient area of existing MCGS, the number of new MCGs to realize has been calculated, taking 4500 sq.m. (the median value of MCGs plot area in the study area) as the reference value for the single plot area.

Once identified the municipalities that need new MCGs and calculated the number of plots that each municipality should allocate, the localization of these new MCGs has been defined. To this end, areas potentially suitable for new MCGs have been identified on the basis of the following criteria: i) proximity to residential road network, because the accessibility to the MCGs is a fundamental requirement for a public service. The methodology, anyway, will consider only the residential road network, usually not characterized by heavy traffic; ii) compatible land-use, in order to exclude areas with a land-use that doesn't allow a future transformation in MCG; iii) not high land capability, in order to allow the preservation of agriculture in one of the more productive area of the Pianura Padana, as one of the possible strategies to contrast urban expansion.

- Firstly, the portion of the road network lying in residential areas has been identified (in red and blue in Figure 5), through a GIS overlay mapping between residential land-uses and the road network. The road network database used is the road graph of the metropolitan area of Milano (Open Street Map) updated in February 2014 and processed in order to rebuild the topological relationships (especially the intersections between the roads features).

- Then, in order to calculate the proximity of MCGs to the residential road network, a service area (SA) analysis on the road network from the existing MCGs has been conducted with ArcGIS. This analysis identified the portions of the residential road network served by existing MCGs (in light blue in Figure 5), that is within the threshold distance of $1300 \mathrm{~m}$ from the existing MCGs, representing the distance cyclable in 10 minutes at a speed of about $8 \mathrm{~km} / \mathrm{h}$ (Rattan $e t$ al., 2012). The percentage of the residential road network served by MCGs has been calculated for each municipality.

- Secondly, considering only the 59 municipalities with MCGs, the mean value is $54 \%$ (i.e., the $54 \%$ of the residential areas is covered by existing MCGs): although the range goes from a minimum value of $0 \%$ (Masate and Basiano) to a maximum of $98 \%$ (Settala and Vignate), the average value seems representative because it is prac-

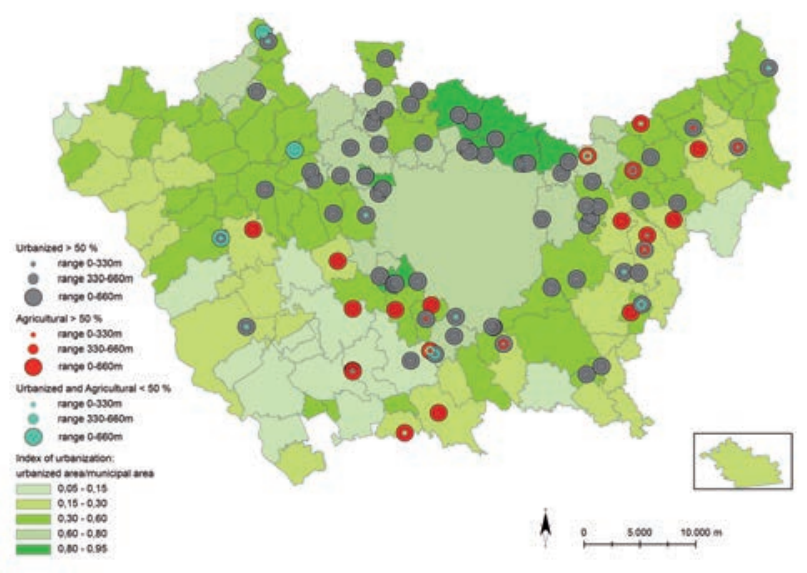

Figure 3. Prevalent land-uses in the municipal community gardens surroundings (Map 2).

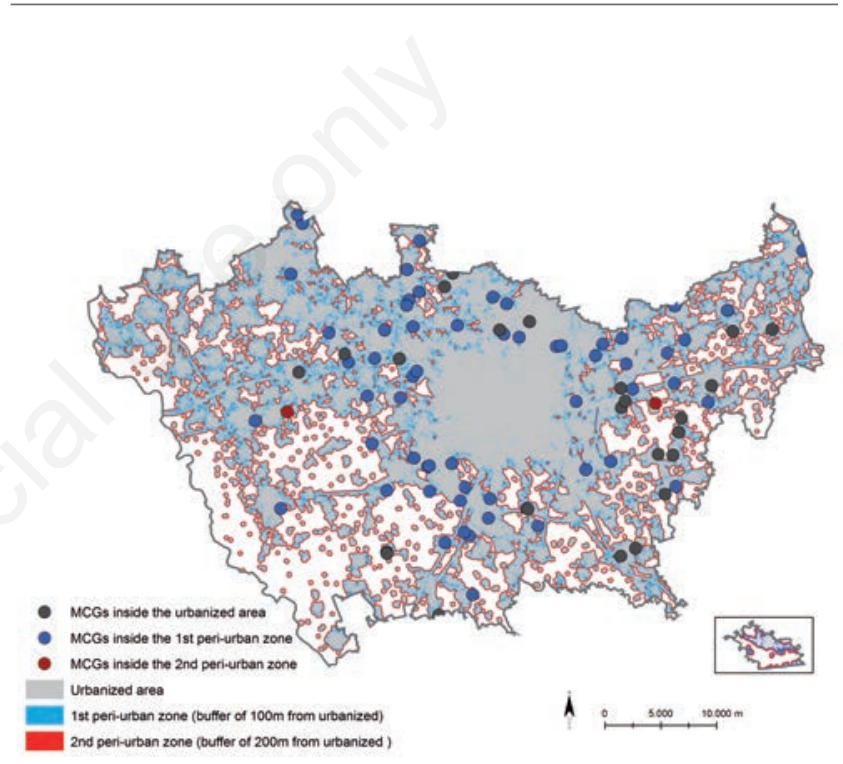

Figure 4. Localization of the municipal community gardens (MCGs) (Map 3).

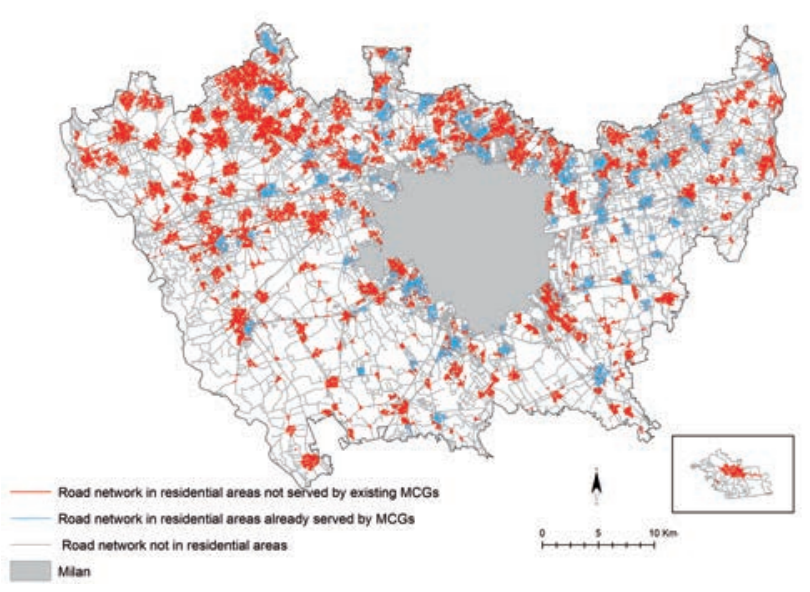

Figure 5. Service area $(1300 \mathrm{~m})$ from existing municipal community gardens (MCGs) (Map 4). 
tically equal to the median (53\%). The distribution is perfect, with each quartile with 15 municipalities (except the second one with 14). Considering all the 133 municipalities of the study area, the mean value decreases to $25 \%$.

- The existing land-uses considered compatible with the eventual transformation into MCGs are: scattered residential, abandoned/not vegetated, not cultivated, cropland and grassland (DUSAF codes: $1121,1122,1123,134,1412,2111,2112,2311,2312$ ).

- Finally, in order to reserve the most productive soils for agricultural uses, areas with soils with land capability class 1 and 2 have been excluded from the possible conversion into MCGs.

The overlay mapping procedure between the areas defined in the three steps described above has generated the potentially suitable and available areas for the realization of new MCGs (Figure 6) with a total area of about 4800 ha.

The available areas for new MCGs for each municipality have been calculated in order to verify if they were sufficient to reach the metropolitan average MCGs area per capita. Only 4 municipalities (Bresso, Sesto San Giovanni, Dresano and Vizzolo Predabissi) have not sufficient available areas for new MCGs to reach the threshold of 0.68 sq.m/inhabit. of MCGs.

Based on the calculated area and number of new MCGs by municipality to achieve, the localization of the plots of new MCGs has been hypothesized, following a criterion of homogenous distribution throughout the municipality. This hypothesis has been used to perform a new Service Area analysis. The new SA (SA2) represents the portion of the residential road network comprised in a distance of $1300 \mathrm{~m}$ from the new MCGs identified, in addition to those already existing.

The 59 municipalities with existing MCGs rose the mean served area from $54 \%$ of SA1 to $74 \%$ of SA2 (i.e., the $74 \%$ of the residential areas is covered by existing MCGs), with a median of $84 \%$.

The new MCGs were added also to the other 74 municipalities without MCGs: considering all the 133 municipalities of the study area, the mean served area increased from $25 \%$ of SA1 to $79 \%$ of SA2. The Figure 7 shows for each municipality the percentage of the residential road network served by the existing MCGs (SA1) and by existing and proposed MCGs (SA2). There are 23 municipalities that have an existing MCGs area in excess (with a thick black boundary in Figure 7): for these, no new MCGs have been proposed because the problem is not an

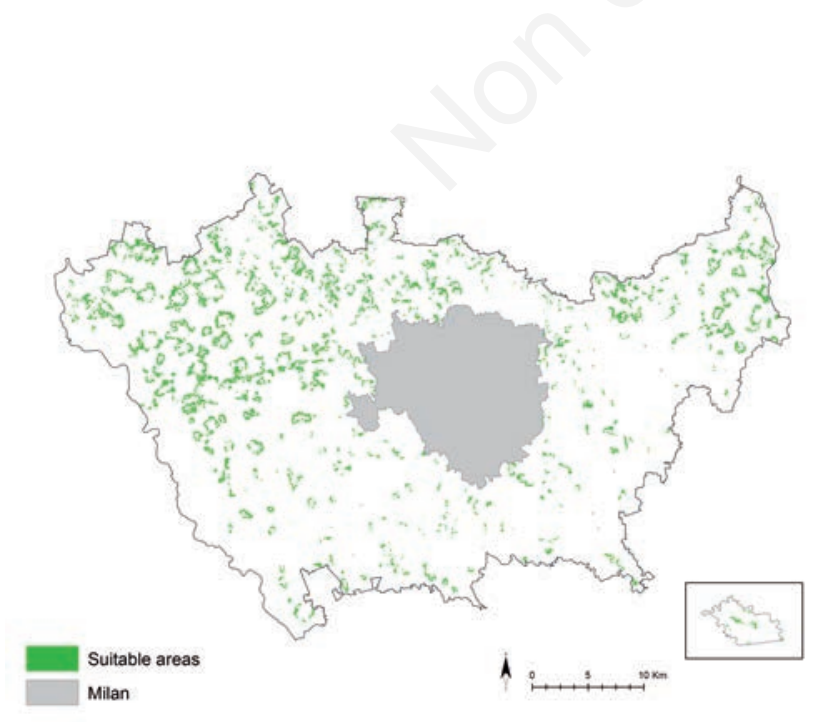

Figure 6. Suitable areas for new municipal community gardens (Map 5). insufficient quantity, but a not optimal distribution.

Only 6 municipalities remain with a percentage of the residential road network served by existing and proposed MCGs service area (SA2) less than 25\%: 4 of them have no new MCGs proposed because they already have an existing MCGs area in excess and the other 2 are municipalities that do not have sufficient area available for new MCGs.

\section{Conclusions}

The realization of MCGs is part of the wider issue of requalification of marginal and urban fringe areas and is an element for improving environmental and life quality in urban and suburban degraded areas. In this sense MCGs represent an urban and social service to improve through decisions supported by careful planning of interventions.

With reference to the approach proposed in this paper can be stated that: i) the analysis from literature, municipal urban plans, existing maps, supplemented by direct survey and realized through GIS, is the starting point to define the situation concerning the supply of MCGs for each municipality; the same analysis allows to identify, from the quantitative point of view, the needs in terms of surfaces and number of MCGs to realize; ii) SA analysis is a valid tool to test the accessibility of MCGs by the residents in the phases of analysis and localization of new sites; iii) the use of GIS, especially during the identification of suitable areas to be allocated to MCGs, allows to consider different territorial characteristics and to modify the processing procedures with the identification of alternative scenarios; on the other hand it is essential the availability of geographical data bases updated and detailed, with particular reference to land use and road network; iv) the proposed methodology for the identification of possible sites suitable to host MCGs, is particularly useful to plan interventions at the provincial level (e.g., definition of a provincial/metropolitan area plan, setting priorities, allocation of funding) while, for the application at the municipal level, it is considered appropriate the integration with direct surveys aimed to verify the characteristics of the identified sites; v) it is necessary to give particular consideration to the question of the ownership of the sites identified and to the urban plan regulations aimed to allow the effective transformation of the lots chosen in MCGs.

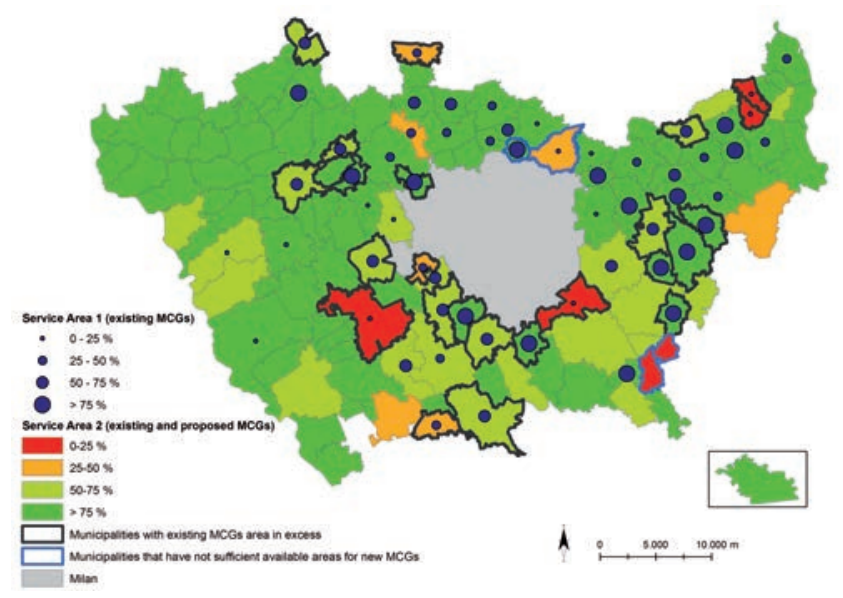

Figure 7. Percentage of the residential road network served by existing and proposed municipal community gardens (MCGs) (Map 6). 


\section{References}

Alberti M. 2005. The effects of urban patterns on ecosystem functions. Int. Reg. Sci. Rev. 28:168-92.

Angotti T. 2015. Urban agriculture: long-term strategy or impossible dream?: Lessons from prospect farm in Brooklyn, New York. Public Health 129:336-41.

Bendt P., Barthel S., Coldinga J. 2012. Civic greening and environmental learning in public-access community gardens in Berlin. Landscape Urban Plan. 109:18-30.

Brock B., Foeken D. 2006. Urban horticulture for a better environment: a case study of Cotonou. Benin. Habitat Int. 30:558-78.

Central Oregon Intergovernmental Council. 2014. Central Oregon community gardening manual. Available from: http://coic2.org/community-development/food-systems/

Colding J., Lundberg J., Folke C. 2006. Incorporating green-area user groups in urban ecosystem management. AMBI0 35:237-44.

Comune di Milano-Zona3. 2006. Studio di fattibilità e progettazione di orti urbani a Milano (a cura di M. Pollastri). Comune di Milano, Milano, Italy.

Comune di Pisa. 2014. Disciplinare di gestione degli orti urbani, ai sensi dell'art. 36 del regolamento per la gestione del patrimonio immobiliare del comune di Pisa; 25 settembre. Comune di Pisa, Pisa, Italy.

Comune di Sassari. 2013. Regolamento comunale orti urbani. Testo coordinato della deliberazione del Consiglio comunale n. 30 del 10 settembre 2013. Comune di Sassari, Sassari, Italy.

Costanza R., d'Arge R., De Groot R., Farber S., Grasso M., Hannon B., Limburg K., Naeem S., O'neill R.V., Paruelo J. 1997. The value of the world's ecosystem services and natural capital. Nature 387:253-60.

FAO. 2014. Growing greener cities in Latin America and the Caribbean - A FAO report on urban and peri-urban agriculture in the region. Available ffrom: http://www.fao.org/3/a-i3696e.pdf

Ghosh S. 2004. Food production in cities. Acta Hort 643:233-9.

Groening G. 2005. The world of small urban gardens. Chron. Hortic. 45:22-5.

Irvinea S., Johnsona L., Petersa K. 1999. Community gardens and sustainable land use planning: a case study of the Alex Wilson community garden. Local Environ. Int. J. Justice Sustain. 4:33-46.

Kaplan S. 1995. The restorative benefits of nature: toward an integrative framework. J. Environ. Psychol. 15:169-83.

Kozlowski J., Hill G. 1993. Towards planning for sustainable development. Avebury-Ashgate Publishing Group, Aldershot, England.

La Rosa D., Spyra M., Inostroza L. 2016. Indicators of cultural ecosystem services for urban planning: a review. Ecol. Indicat. 61:74-89.

Lawson L. 2004. The planner in the garden: a historical view into the relationship between planning and community gardens. J. Plan. History 3:151-76.

Lin B.B., Philpott S.M., Jha S. 2015. The future of urban agriculture and biodiversity-ecosystem services: challenges and next steps. Basic Appl. Ecol. 16:189-201.

Muratet A., Fontaine B. 2015. Contrasting impacts of pesticides on butterflies and bumblebees in private gardens in France. Biol. Conserv. 182:148-54.

Okvat H., Zautra A.J. 2011. Community gardening: a parsimonious path to individual, community, and environmental resilience. Am. J. Commun. Psychol. 47:374-87.

Orsini F., Kahane R., Nono-Womdim R., Gianquinto G. 2013. Urban agriculture in the developing world: a review. Sustain. Dev. 33:695-720.

Qadir M., Ghafoor A., Murtaza G. 2000. Cadmium concentration in vegetables grown on urban soils irrigated with untreated municipal sewage. Environ. Dev. Sustain. 2:11-9.

Rattan A., Campese A., Eden C. 2012. Modeling walkability. Arc. User. Winter 2012:30-3.

Regione Lombardia. 2015. Legge Regionale 1 luglio 2015 , n. 18 - Gli orti di Lombardia. Disposizioni in materia di orti didattici, sociali periurbani, urbani e collettivi. Available from: http://normelombardia. consiglio.regione.lombardia.it/NormeLombardia/Accessibile/main. aspx?iddoc $=\operatorname{lr} 002015070100018 \&$ view $=$ showdoc

Reyes M., Páez A., Morency C. 2014. Walking accessibility to urban parks by children: a case study of Montreal. Landscape Urban Plann. 125:38-47.

Rosol M. 2010. Public participation in post-fordist urban green space governance: the case of community gardens in Berlin. Int. J. Urban Reg. Res 34:548-63.

Säumel I., Kotsyuk I, Hölscher M., Lenkereit C., Weber F., Kowarik I. 2012. How healthy is urban horticulture in high traffic areas? Trace metal concentrations in vegetable crops from plantings within inner city neighborhoods in Berlin, Germany. Environ. Pollut. 165:124-32.

Senes G., Toccolini A. 1998. The EPP method (Environmental Precondition Plan) for sustainable rural land use planning. 13th International Congress on Agricultural Engineering, 2-6 February, Rabat, Morocco.

Somenahalli S., Shiptonb M. 2013. Examining the distribution of the elderly and accessibility to essential services. Social Behav. Sci. 104:942-51.

Thibert J. 2012. Making local planning work for urban agriculture in the North American context: a view from the ground. J. Plan. Educ. Res. 32:349-57.

University of Missouri. 2009. Community gardening toolkit. Available from: http://extension.missouri.edu/p/MP906-6

Van den Berg A.E, van Winsum-Westra M., de Vries S., van Dillen, S.M.E. 2010. Allotment gardening and health: a comparative survey among allotment gardeners and their neighbors without an allotment. Environ. Health 9:74-86.

Wang J., Kwan M., Ma L. 2014. Delimiting service area using adaptive crystal-growth Voronoi diagrams based on weighted planes: a case study in Haizhu District of Guangzhou in China. Appl. Geogr. 50:108-19. 